\title{
Hospital Pharmacists in Europe: Between Warehouse and Prescription Pad?
}

\author{
Livio Garattini ${ }^{1} \cdot$ Anna Padula $^{1}$
}

Published online: 2 February 2018

(C) The Author(s) 2018. This article is an open access publication

\section{Introduction}

Traditionally, pharmacy has long been regarded as a transitional discipline between health and chemistry [1]. However, since the 1950s the large-scale manufacturing of medicinal products by the pharmaceutical industry has limited the role of pharmacists to mainly compounding, dispensing and labeling drugs prescribed by physicians. Nowadays, pharmacists practice in a variety of settingscommunity and hospital pharmacies, regulatory and health authorities, pharmaceutical industry and research—and are generally recognized as drug experts regardless of their specific role. Although scientific knowledge is still the core of pharmacy education, pharmacists now seem to perceive it as somehow less relevant, and consider clinical patientcentered activities to be increasingly important [2], recently also including prescribing, claiming that the pharmacist's involvement is vital to reducing clinical errors [3].

Here we focus on hospital pharmacists (HPhs), a historically recent profession, which still includes only a minority of pharmacy graduates (in Europe [4] and elsewhere), to analyze the 'state of the art' of this specific role, whose professional tasks are still debated in many European countries.

Livio Garattini

lgarattini@marionegri.it

1 Mario Negri Institute for Pharmacological Research, Bergamo, Italy

\section{European Framework}

After baseline pharmacy education [5], most European countries schedule a specialization in hospital pharmacy [6] (Fig. 1), which is mandatory and can even last 4 years in large continental countries such as France, Italy and Spain. According to the European Association of Hospital Pharmacists (EAHP), "hospital pharmacy is the health care service which comprises the art, practice, and profession of choosing, preparing, storing, compounding and dispensing medicines and medical devices, advising healthcare professionals and patients on their safe, effective and efficient use" [7]. Thus, HPhs should perform (or at least supervise) drug ordering, purchasing, and storage and supply in hospital, even reviewing and validating all prescriptions if possible [8]. The (few) medicines that still require manufacture or compounding should be produced in the hospital pharmacy, or outsourced under its responsibility. Broadly, the number of hospital pharmacies across Europe producing medicines for stock and individual prescriptions has substantially decreased since 2000 [9].

From a clinical viewpoint, HPhs should assess the appropriateness of all patients' medicines, and pharmacy services should continuously evolve to optimize clinical outcomes [8] so as to ensure that seven 'rights' are always respected for all pharmaceutical therapies provided to inpatients/outpatients at hospital: right patient, right dose, right route, right time, right drug, right information and right documentation. According to an EAHP survey, clinical activities in European hospital pharmacies have not yet been well-documented and their clinical services were not very well implemented until recently [10]. 
Fig. 1 Duration of hospital pharmacy master degrees in the main Western European countries [6]. $N L$ Netherlands

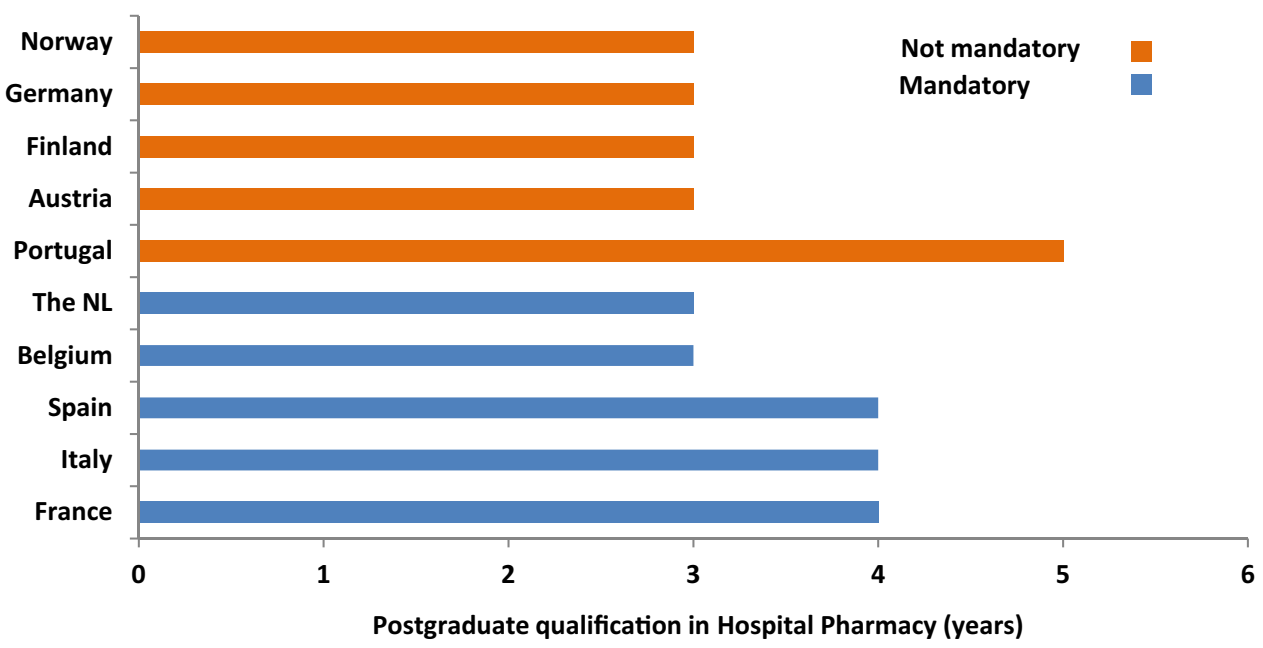

to patients, shifting their focus from the product to the patient; European countries are no exception [15, 16]. The involvement in clinical pharmacy work is perceived worldwide as a highly motivating improvement in the HPh's career ladder, moving beyond the routine functions of medicine supply [17], which can be partially devolved to pharmacy technicians in countries such as the UK, where this occupational category is formally classified and wellestablished in the healthcare service [13]. Besides reducing the risk of clinical errors [18], even more general improvements (e.g. reduced admissions and length of stay) have been enthusiastically reported in the flourishing literature following the introduction of $\mathrm{HPh}$ prescribing in the UK [11]. However, although it seems realistic to expect that clinical pharmacy services in inpatient care are likely to result in improved care [19], it is hard to standardize most $\mathrm{HPh}$ interventions, and current clinical evidence is mainly based on small-sample studies conducted in single facilities [20], whose results are hard to generalize by definition. These studies often seem to be induced by a need for $\mathrm{HPhs}$ to demonstrate the usefulness of the service they provide to their hospital boards [21]. Related (and partly consequent) to the scant clinical evidence, all the reviews on economic evaluations of clinical pharmacy services have shown that most analyses suffer from a poor design [22], and their methodology might have even got worse in recent times [23].

Since the traditional monopoly of medical doctors on prescribing has already been 'encroached upon' by nurses in some European countries such as Belgium, Ireland and the UK [11, 16], the latest 'hot argument' is why some prescription rights should not be devolved to HPhs in all European countries, similarly to what happens in other continents (e.g. Australia, Canada, New Zealand, the US). However, according to a critical review of the literature on supplementary prescribing in the UK [24], the 
methodological weakness of the published small-scale empirical studies does not support this claim. Moreover, the UK's particular experience, opposed by the medical profession from the outset [25], might have been somehow favored by the shortage of medical doctors in the NHS at that time [14]; thus, it is hardly transferable to other European countries.

In general, although prescription rights in hospitals seem more reasonable than in the community [26], the pros and cons of HPh prescribing have already been debated and this long discussion is very unlikely to terminate with a general consensus [27]. The right to prescribe requires an appropriate baseline background (including diagnostics) and continuing professional education, but above all implies that HPhs are legally responsible for the patient's outcomes resulting from her/his decisions [28]. Therefore, if an $\mathrm{HPh}$ wants the right to prescribe, she/he must also implicitly accept legal responsibilities; however, not all $\mathrm{HPhs}$ in European countries would necessarily be pleased to accept them [27], particularly in the present era of 'defensive medicine', when clinical errors can induce high legal costs for accountable health professionals [29].

\section{Comment}

The HPh's role in Europe still seems rather confused from an outsider's viewpoint, and many statements by the EAHP sound like common sense (e.g. the seven rights) to mask a perceived identity crisis. This new wave of clinical pharmacy seems more a reaction against a perceived demotion of the role after the manufacturing revolution, rather than a credible follow-on evolution.

After a couple of decades, the evidence of the clinical efficacy and cost effectiveness of these activities is still very controversial. The former is scant, mainly because $\mathrm{HPh}$ clinical activities are hard to standardize by definition, and hence also their outcome measures in trials, while the latter's major drawback is the questionable trade-off between HPh additional costs and potential savings on other healthcare services. Besides the intrinsic limits of any economic evaluation in healthcare [30], a specific limit in this field is that economic techniques are applied to local choices of organization and management inspired by political objectives [22]; thus, results may be substantially affected by the aims of whoever conducted the study, and be hardly extendable to other hospital settings.

Last but not least, the claim to extend prescribing rights to HPhs seems another arguable strategy. Despite the emphasis on the very particular British experience, this choice requires strong clinical knowledge (including diagnostic skills), implies legal responsibilities, and is eventually very likely to bring HPhs into conflict with medical doctors, who have traditionally played the prescriber role in hospital.

Rather than supporting these controversial tendencies, we believe that European HPhs could strengthen their professional role better in different ways. Here we offer at least two suggestions. First, being in the right position of drug experts to advise prescribers, HPhs should exploit further their pivotal role of pharmaceutical 'gatekeepers' by improving the appropriateness of prescriptions and, hopefully, generating considerable savings, making public pharmaceutical expenditure more sustainable [31]; for instance, by selecting the most appropriate therapies for hospital procurement, specializing in specific areas of expertise, and affirming their independent opinions within multidisciplinary teams to enhance cost-effective prescribing. Second, since medical devices are now part of their storage and supply work, HPhs could boost their knowledge on this massive and heterogeneous class of products, varying from syringes to medical stents. The clinical evidence regarding these products might be usefully taught in master degrees for hospital pharmacy.

Finally, beyond questionable debates on the evolution of their role, it goes without saying that any $\mathrm{HPh}$ can provide a good clinical service on a daily basis, wherever she/he works and regardless of the hospital organization, just like any healthcare professional who does her/his job in the interests of patients.

\section{Compliance with Ethical Standards}

Funding No funding to declare for this article.

Conflict of interest Anna Padula and Livio Garattini have no conflicts of interest.

Open Access This article is distributed under the terms of the Creative Commons Attribution-NonCommercial 4.0 International License (http://creativecommons.org/licenses/by-nc/4.0/), which permits any noncommercial use, distribution, and reproduction in any medium, provided you give appropriate credit to the original author(s) and the source, provide a link to the Creative Commons license, and indicate if changes were made.

\section{References}

1. Pearson GJ. Evolution in the practice of pharmacy-not a revolution! CMAJ. 2007;176(9):1295-6.

2. Waterfield J. Is pharmacy a knowledge-based profession? Am J Pharm Educ. 2010;74(3):50.

3. Sweeney MA. Physician-pharmacist collaboration: a millennial paradigm to reduce medication errors. J Am Osteopath Assoc. 2002;102(12):678-81.

4. PHARMINE. Pharmacy education in Europe. Countries profiles. https://www.pharmine.org/country-profiles/. Accessed Dec 2017.

5. Garattini L, Padula A. From pharmacy faculty to pharmacy shop: still a logical pathway in Europe? Drugs Ther Perspect. 2018;34(2):85-8. 
6. European Association of Hospital Pharmacists. Members. http:// www.eahp.eu/about-us/members. Accessed Dec 2017.

7. European Association of Hospital Pharmacists. Hospital pharmacy. http://www.eahp.eu/hp-practice/hospital-pharmacy. Accessed Dec 2017.

8. Anonymous. The European statements of hospital pharmacy. Eur J Hosp Pharm 2014;21:256-8.

9. Frontini R, Miharija-Gala T, Sykora J. EAHP survey 2010 on hospital pharmacy in Europe: part 3. Production and quality assurance. Eur J Hosp Pharm. 2012;19:510-3.

10. Frontini R, Miharija-Gala T. SykoraJ. EAHP survey 2010 on hospital pharmacy in Europe: parts 4 and 5. Clinical services and patient safety. Eur. J Hosp Pharm. 2013;20:69-73.

11. Fisher J, Kinnear M, Reid F, Souter C, Stewart D. What supports hospital pharmacist prescribing in Scotland? A mixed methods, exploratory sequential study. Res Social Adm Pharm. 2017. (pii: S1551-7411(16)30520-4).

12. Sosabowski M, Gard P. Pharmacy education in the United Kingdom. Am J Pharm Educ. 2008;72(6):130.

13. Schafheutle EI, Jee SD, Willis SC. Fitness for purpose of pharmacy technician education and training: the case of Great Britain. Res Soc Adm Pharm. 2017;13(1):88-97.

14. Surugue J, Vulto A. Workforce of EU hospitals and pharmacy services: a direct patient safety issue. EHJP practice fall 2006. Special supplement. https://ec.europa.eu/health/archive/ph_ systems/docs/ev_20080617_rd03_en.pdf. Accessed Dec 2017.

15. Auta A, Maz J, Strickland-Hodge B. Perceived facilitators to change in hospital pharmacy practice in England. Int $\mathrm{J}$ Clin Pharm. 2015;37(6):1068-75.

16. De Rijdt T, Desplenter F. Hospital pharmacy in Belgium: from moving boxes to providing optimal therapy. Can J Hosp Pharm. 2016;69(2):156-66.

17. Guiu Segura JM. Advancing into a future hospital pharmacy practice model: the value of the basel statements. Int J Pharm Pract. 2015;23(2):162-3.

18. Kearney A, Halleran C, Walsh E, Byrne D, Haugh J, Sahm LJ. Medication reviews by a clinical pharmacist at an Irish University Teaching Hospital. Pharmacy (Basel). 2017;5(4):60.

19. Viktil KK, Blix HS. The impact of clinical pharmacists on drugrelated problems and clinical outcomes. Basic Clin Pharmacol Toxicol. 2008;102(3):275-80.
20. Kaboli PJ, Hoth AB, McClimon BJ, Schnipper JL. Clinical pharmacists and inpatient medical care: a systematic review. Arch Intern Med. 2006;166(9):955-64.

21. Campbell G, Auyeung V, McRobbie D. Clinical pharmacy services in a London hospital, have they changed? Int J Clin Pharm. 2013;35(5):688-91.

22. De Rijdt T, Willems L, Simoens S. Hospital pharmacists versus hospital administrators: a struggle for clinical pharmacy services. Expert Rev Pharmacoecon Outcomes Res. 2009;9(6):497-8.

23. Gallagher J, McCarthy S, Byrne S. Economic evaluations of clinical pharmacist interventions on hospital inpatients: a systematic review of recent literature. Int $\mathbf{J}$ Clin Pharm. 2014;36(6):1101-14.

24. Cooper RJ, Anderson C, Avery T, Bissell P, Guillaume L, Hutchinson A, et al. Nurse and pharmacist supplementary prescribing in the UK: a thematic review of the literature. Health Policy. 2008;85(3):277-92.

25. Dawoud D, Griffiths P, Maben J, Goodyer L, Greene R. Pharmacist supplementary prescribing: a step toward more independence? Res Social Adm Pharm. 2011;7(3):246-56.

26. Garattini L, Padula A. Pharmaceutical care in Italy and other European countries: between care and commerce? Postgrad Med. 2018;130(1):52-4.

27. Hopf Y, Mansell H. Should hospital pharmacists prescribe? Can J Hosp Pharm. 2014;67(5):390-3.

28. Emmerton L, Marriott J, Bessell T, Nissen L, Dean L. Pharmacists and prescribing rights: review of international developments. J Pharm Pharm Sci. 2005;8(2):217-25.

29. Rothberg MB, Class J, Bishop TF, Friderici J, Kleppel R, Lindenauer PK. The cost of defensive medicine on three hospital medicine services. JAMA Intern Med. 2014;174(11):1867-8.

30. Garattini L, Padula A. Dutch guidelines for economic evaluation: 'from good to better' in theory but further away from pharmaceuticals in practice? J R Soc Med. 2017;110(3):98-103.

31. Garattini L, Padula A. 'Appropriateness' in Italy: a 'magic word' in pharmaceuticals? Appl Health Econ Health Policy. 2017;15(1):1-3. 